\title{
NORMAS ISO NÃO CERTIFICÁVEIS QUE APOIAM A ISO 9001:2015: PROPOSIÇÃO DE MODELO DE UTILIZAÇÃO E GERENCIAMENTO
}

\author{
Maria Helena Lasserre Ferreira (UFPE - CAA) mhelenalasserre@ gmail.com \\ Renata Maciel de Melo (UFPE - CAA) renatamaciel0@gmail.com
}

\section{Resumo}

Para que um Sistema de Gestão da Qualidade possa ser implementado, funcionar em plenitude e atender a seus objetivos é necessária a participação, esforço e planejamento de todos aqueles que compõem a organização. A certificação ISO 9001 demonstra ao mercado que as organizações atendem padrões internacionais. Isto representa, em algumas situações, um fator de diferenciação frente a seus concorrentes ou fator de qualificação para estar apto a entrar no mercado. Logo, muitas empresas apresentam dificuldade de adequação às exigências da ISO 9001. Com a finalidade de auxiliar a organização a utilizar Normas ISO ligadas a qualidade, esse trabalho tem como objetivo propor um modelo de utilização e gerenciamento baseado nas normas ISO não certificáveis (aqui também tratadas por normas ISO de Apoio) que dão suporte à ISO 9001:2015, por meio da Metodologia de Sistemas Soft de Checkland como suporte para o delineamento do modelo. Estas normas ISO de apoio vêm ganhando espaço ao ficar claro o potencial de transformação para as organizações, já que elas são um detalhamento de pontos importantes de um SGQ.

Palavras-Chaves: Sistemas de Gestão da Qualidade, Normas ISO, Metodologia de Sistemas Soft de Checkland.

\section{Introdução}

Com o desenvolvimento contínuo da Gestão da Qualidade, gerado pela competitividade crescente nos mercados e maiores exigências dos consumidores, organizações e seus administradores se viram obrigados a aperfeiçoar e refinar seus Sistemas de Qualidade.

Desse modo, com a elevada complexidade de entidades e seus relacionamentos sendo considerados na Gestão da Qualidade, documentações e atividades para a mútua confiança entre parceiros se fez necessária. Isso finalmente resultou na emissão da série ISO 9000, que definiu os requerimentos básicos para a gestão da qualidade (WECKENMANN; AKKASOGLU; WERNER, 2015). 
A norma ISO 9001:2015, fornece as bases para a implementação do Sistema de Gestão da Qualidade (SGQ), auxiliando na padronização de processos e controle de documentações. Além disso, por apresentar caráter de certificação, a norma atribui às empresas por ela certificadas um padrão de qualidade de extrema relevância às partes interessadas, podendo promover e facilitar a entrada em novos mercados. Ademais, a implementação gera maior confiança aos produtos e serviços da organização, redução de custos, maior satisfação de clientes, facilita a exportação, já que as especificações da ISO ditam um padrão internacional, além de promover uma cultura da qualidade entre a organização.

Embora a ISO 9001 seja frequentemente trabalhada e estudada, esta não engloba toda a prática da Gestão da Qualidade. Existem normas que dão suporte ao SGQ, as Normas ISO não certificáveis que apoiam a ISO 9001:2015. Estas, neste trabalho também tratadas por Normas ISO de apoio, são fundamentais para a estruturação de um Sistema de Gestão da Qualidade eficiente e eficaz. O tema vem ganhando espaço ao ficar claro o potencial de transformação que as normas ISO de apoio apresentam para as organizações, já que elas são um detalhamento de pontos importantes de um SGQ.

Buscando promover maior entendimento e aplicação das Normas ISO não certificáveis ligadas à qualidade, gerando benefícios organizacionais, esse trabalho procura apresentar um modelo de utilização e gerenciamento baseados nas Normas ISO de apoio de modo que promova embasamento para a implementação e manutenção do SGQ, esclarecendo a ISO 9001 e possíveis problemas de adaptação ao SGQ por ela promovido.

\section{As normas ISO de apoio}

Baseada no ciclo PDCA, a ISO 9001 estimula a manutenção de um ciclo de melhoria contínua no ambiente gerencial e, consequentemente, na organização como um todo, o que evidencia melhorias para a organização. Karapetrovic e Willborn (2001) apontam que pesquisadores veem muitos benefícios de mercado do sistema, como melhorias da imagem da empresa, menores números de reclamações, melhor comunicação com clientes, melhoramento da satisfação de clientes e de sua rentabilidade além de maior confiança para a organização. 


\subsection{ISO 10014:2008 (ABNT, 2008) - Diretrizes para a percepção de benefícios financeiros e econômicos}

Endereçada à Alta Direção, reforça os Princípios da Gestão apresentados na ISO 9001:2015, dentre suas contribuições está a definição de cinco Níveis de Maturidade para a organização, que variam de 1(para empresas onde a prática do dos princípios de gestão ainda não é encontrada ou não foi implementada) a 5(quando esta é desdobrada em toda a organização).

Dessa forma, o grau de maturidade obtido por meio do modelo da ISO 10014:2008 permite à empresa um melhor entendimento de sua situação quanto às práticas de gestão também presentes na ISO 9001(devido à distância em tempo das duas versões da série, a ISO 10014:2008 aponta 8 princípios gerenciais enquanto a ISO 9001:2015 aponta 7, no entanto estes são completamente equivalentes) e evidencia quais desses princípios merecem maior atenção.

\subsection{ISO 10018:2013 (ABNT, 2013) - Gestão de qualidade - Diretrizes para envolvimento das pessoas e suas competências}

A ISO 10018:2013 fornece diretrizes para o tratamento de fatores humanos que auxiliam em questões referentes ao envolvimento e competência que possam influenciar positivamente as relações entre colaboradores e desses com o próprio SGQ, cooperando para que os objetivos da organização sejam atingidos.

Mais especificamente, ela recomenda cinco passos para atingir os níveis atuais de envolvimento e competência, e para identificar lacunas entre o status quo e o que a organização precisa no intuito de ser eficaz em seu mercado (BOYS; WILCOCK, 2014). A ISO 10018:2013 se debruça, então, sobre os fatores humanos. Para cada um desses valores são propostas ações que podem ser tomadas a fim de fortalecer o envolvimento de pessoas e atingir as necessidades individuais referentes às necessidades do SGQ.

2.3. ISO 10006:2006 (ABNT, 2006) - Sistemas de gestão da qualidade - Diretrizes para a gestão da qualidade em empreendimentos 
As diretrizes na norma ISO 10006:2006 são endereçadas a usuários de diversos perfis. São aplicáveis a empreendimentos, independentemente de serem pequenos ou grandes, simples ou complexos, individuais ou fazendo parte de um programa ou carteira de empreendimentos (ABNT, 2006). Ela destaca dois aspectos a considerar na aplicação da gestão da qualidade em empreendimentos: processo do empreendimento e produto do empreendimento. Enfatiza a responsabilidade da alta direção para alcançar os objetivos da qualidade do empreendimento. Aborda, ainda, diretrizes de como deve ser a avaliação do processo, gestão de recursos e realização do produto.

\subsection{ISO 10019:2007 (ABNT, 2007) - Diretrizes para a seleção de consultores de Sistemas} de Gestão da Qualidade e uso de seus serviços

A ISO 10019:2007 orienta o processo de avaliação de competência de um consultor de SGQ e dá a confiança de que as necessidades e expectativas da organização com relação aos serviços do consultor serão satisfeitas (ABNT, 2007). Assim, traz aspectos fundamentais a serem considerados no processo de seleção de um consultor de sistema de gestão da qualidade e no uso de serviços de consultoria de sistema de gestão da qualidade.

2.5. Documento Orientativo (D.O) do Comitê Brasileiro de Qualidade (CB-25, 2011) Orientações para a seleção e contratação de serviços de consultoria treinamento e certificação de sistemas de gestão da qualidade

Silva e Melo (2017) afirmam que o D.O divulga as informações necessárias que possam dar suporte aos interessados em adquirir a certificação do SGQ para sua organização, auxiliando e complementando para isso a norma ABNT NBR ISO 9001. Assim, destina três de suas partes a orientações para a seleção e contratação de serviços de auditoria, treinamento e certificação, respectivamente.

2.6. ISO 10017:2005 (ABNT, 2005) - Guia sobre técnicas estatísticas para ABNT NBR ISO 9001:2000 
Como apontando em sua introdução, a ISO 10017 pretende guiar e auxiliar as organizações a considerar e selecionar técnicas estatísticas apropriadas às necessidades da organização. Aponta, então, a identificação das necessidades potenciais de técnicas estatísticas, quais são aplicáveis a essas necessidades e descreve essas mesmas técnicas.

\subsection{ISO 19011:2018 (ABNT, 2018) - Diretrizes para auditoria de sistemas de gestão}

O documento fornece orientação para todos os tamanhos e tipos de organizações e auditorias de variados escopos e dimensões, incluindo aquelas conduzidas por grandes equipes de auditoria, usualmente de organizações maiores, e aquelas conduzidas por auditores únicos, em organizações grandes ou pequenas (ABNT, 2018). Concentrando-se em auditorias de primeira e segunda parte, trata do gerenciamento de um programa de auditoria, da condução de uma auditoria, das competências e da avaliação de auditores.

\subsection{ISO 10015:2001 (ABNT, 2001) - Diretrizes para treinamento}

A ISO 10015 é uma norma que auxilia à ISO 9001, um sistema de gestão da qualidade implementado com uma abordagem de desenvolvimento de recursos humanos em organizações para identificar e melhorar o processo educacional, que tenta prover uma educação mais efetiva em organizações, resultando em eficácia dos períodos e treinamento (ZAKERIAN et al, 2017). Vê o treinamento como um processo de quatro estágios, auxilia na definição das necessidades de treinamento, sua execução e avaliação de seus resultados.

\subsection{ISO 10002:2005 (ABNT, 2005) - Diretrizes para o tratamento de reclamações nas organizações}

Como apresentado pela própria norma, a ISO 10002:2005 fornece orientação para o projeto e implementação de um processo eficaz e eficiente de tratamento de reclamações para todos os tipos de atividades comerciais e não comerciais, incluindo aquelas relacionadas ao comércio eletrônico. Pretende-se beneficiar uma organização e seus clientes, reclamantes e outras partes 
interessadas. Segundo Hughes e Karapetrovic (2006), ela também foca em garantir que os clientes sejam tratados satisfatoriamente e que existem processos necessários, como recebimento e reconhecimento de reclamações, para o tratamento efetivo de reclamações e satisfação do cliente.

\subsection{ISO 10004:2013 (ABNT, 2013) - Satisfação de cliente - Diretrizes para monitoramento e medição}

Fornece diretrizes sobre a definição e execução dos processos que monitoram e medem a satisfação dos clientes, focando nos clientes externos à organização. Contempla os conceitos e princípios guia para a satisfação de clientes, estrutura para o monitoramento e medição, planejamento, design e desenvolvimento do processo, operação, manutenção e melhoramento do mesmo.

\subsection{ISO 9004:2018 - Gestão da qualidade - Qualidade de uma organização - Orientação para alcançar o sucesso sustentado}

Russel (2003) aponta que a ISO 9004 foi planejada para o uso da alta direção e companhias podem utilizá-la para melhorar a performance organizacional, reduzir custos, satisfazer clientes e melhorar a competitividade. Ela promove a autoavaliação como uma ferramenta importante para a análise crítica do nível de maturidade da organização, abrangendo sua liderança, estratégia, sistema de gestão, recursos e processos, para identificar pontos fortes e fracos, oportunidades tanto de melhoria quanto inovação, ou ambas (ABNT, 2010). Além disso sua aplicação deve facilitar a transição para um programa SGQ total que requer uma mudança organizacional mais profunda e deveria criar tal cultura onde uma forte, comprometida e motivadora liderança está presente e onde os funcionários estão motivados (BOYS et al., 2004; RIBIÈRE; KHORRAMSHAHGOL, 2004; WILCOCK et al., 2006). 


\section{Metodologia de Sistemas Soft de Checkland (SSM)}

Proposta por Checkland em seu artigo Towards a systems-based methodology for real-world problem solving, sua metodologia para sistemas soft lida com problemas reais, não estruturados. Por meio do Processo dos Sete Estágios, busca atingir a resoluções para problemas que estão nas propriedades soft de uma organização. Essa metodologia se baseia na abordagem sistêmica e a reflete, apropriadamente, tratando isoladamente cada aspecto de um problema, para se alcançar o sucesso do todo, podendo ser aplicado em ambientes nos quais a questão principal não é "como fazer” e sim “o que se deve fazer” (CHECKLAND, 1972; SILVA; DE MEDEIROS, 2006). Os sete estágios dessa metodologia são descritos no Quadro 1

Quadro 1 - Metodologia de Sistemas Soft de Checkland: O Processo dos Sete Estágios 


\section{Metodologia de Sistemas Soft de Checkland: O Processo dos Sete Estágios}

1. Situação Problema : Identifica e procura a situação problema da organização

2. Expressar a Situação Problema: O estágio envolve a identificação dos elementos soft ligados ao problema/situação, com a produção da rich picture, figura que expressa o problemas envolvendo desenhos e figuras, fazendo uso de imagens e símbolos para representar todos os elementos da situação problema.

3. Formular as definições "raiz" dos sistemas relevantes: Envolve analisar a rich picture considerando uma visão global da situação problema. Busca, então, soluções baseada nos diferentes pontos de vistas das partes interessadas envolvidas no problema, o ambiente da situação, cultura, normas, valores e relações. É nesse tópico que Checkland apresenta a a análise CATWOE para a identificação de diferente perspetivas.

4. Modelos conceituais dos sistemas nomeados nas situações "raiz": A fase de definições "raiz" é convertida modelos conceituais, considerando como o sistema funcionará para que sejam atendidos seus objetivos. Normalmente essa etapa envolve diagramas que ilustram o processo do sistema e as informações de sua configuração.

5. Comparações no mundo real e modelos: Consiste na comparação do modelo desenvolvido no estágio Modelos conceituais dos sistemas nomeados nas situações "raiz" com a rich picture desenvolvida no estágio Expressar a Situação Problema, levando a discussão e debate da situação atual e identificando espaços para melhorias.

6. Definir as mudanças que são desejáveis e possíveis: Este estágio reúne todos os estágios e é formada uma análise, e mudanças que são desejáveis e realizáveis são consideradas. São consideradas também todos as percepções dos participantes e das pessoas diretamente ligadas à situação problema. Assim, são tomadas as decisões finais que são acordadas por todos os stakeholders da situação.

7. Agir a fim de melhorar a situação do mundo real: São, então, executadas as ações e estratégias planejadas. Contando com a participação de todos os membros envolvidos, são alocadas a funções e responsabilidades que os cabem. São, também, feitas revisões contínuas a fim de garantir que o sistema está progredindo como planejado, de forma cíclica até que o problema inicial esteja resolvido. 


\section{Etapas da vida de um sistema de gestão da qualidade}

$\mathrm{Na}$ busca por gerar uma forma de integração eficiente das normas ISO de apoio foi notado que algumas dessas normas são mais pertinentes de acordo com o momento em que o SGQ se encontra. Para tanto, o Sistema de Gestão da Qualidade Baseado na ISO 9001:2015, para os parâmetros do modelo proposto, conta com quatro etapas: Planejamento; Implementação; Manutenção e Melhoria. Estas referem-se aos momentos de vida do SGQ existentes na empresa e englobam uma seleção de Normas ISO de suporte de extrema relevância para cada fase da vida do SGQ. As quatro etapas consideradas no modelo podem ser vistas no Quadro 2. 


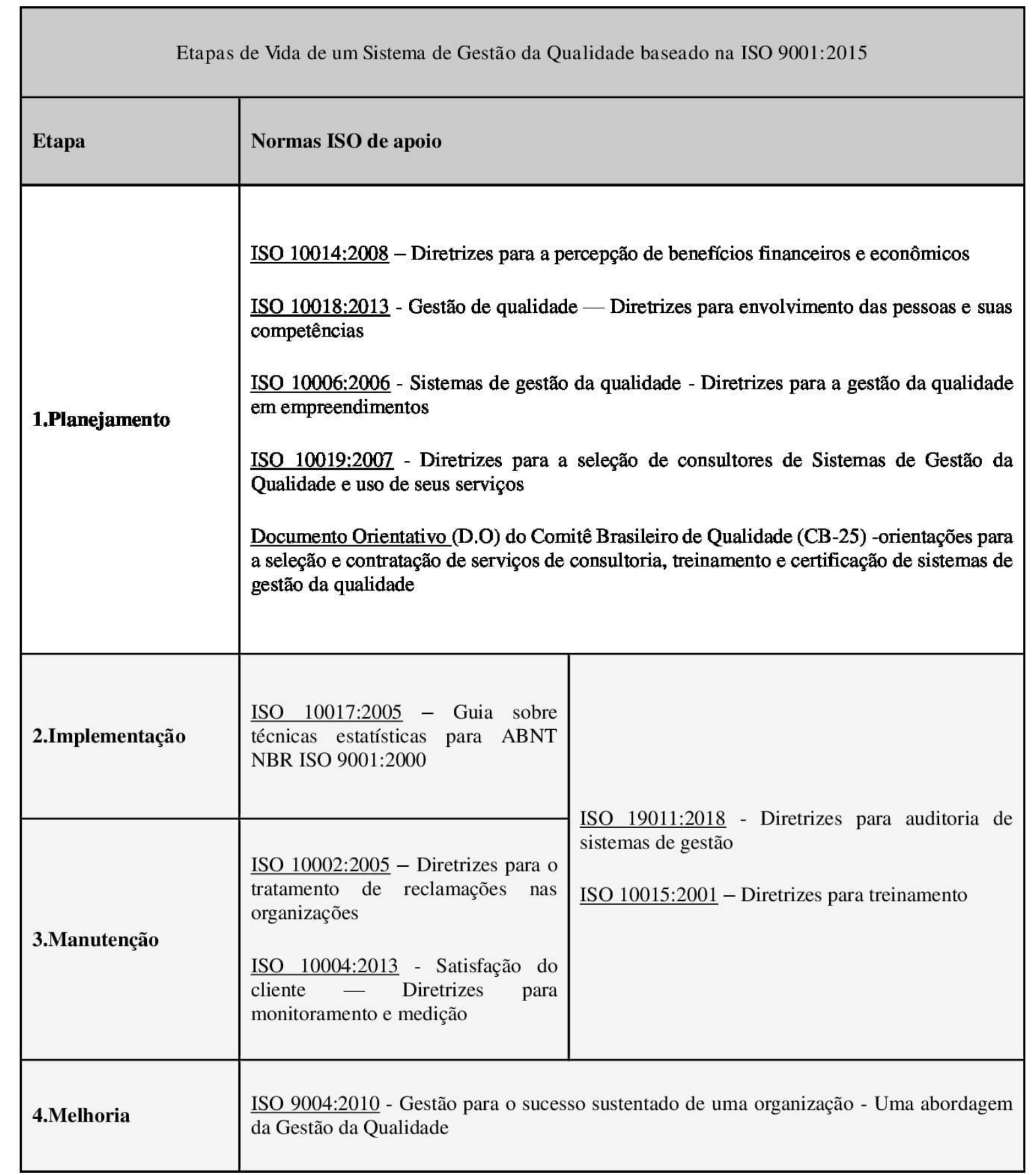

Fonte: Os Autores (2020)

\subsection{Planejamento}

Uma vez decidida pela adoção do SGQ, é fundamental que todo o caminho percorrido nesse processo seja acompanhado e promovido pela Alta Direção da organização. São função dela e do seu Gestor da Qualidade todas as decisões e ações tomadas em relação ao SGQ, cabendo a eles delinear como agirá a empresa nessa área. 
A ISO 9001:2015 aponta que a organização deve determinar questões externas e internas pertinentes para seu propósito e para seu direcionamento estratégico e que afetem sua capacidade de alcançar os resultados pretendidos do SGQ, assim, durante o planejamento das ações a gerência deve determinar informações pertinentes que contribuam para o delineamento do sistema e das ações gerenciais. As quatro Normas ISO de Apoio e o Documento Orientativo (D.O) contidos na etapa Planejamento podem contribuir desse modo.

\subsection{Implementação}

Uma vez planejada como se estruturará o sistema de gestão da qualidade com base na ISO 9001, a etapa de Implementação se preocupa em preparar toda a organização para as mudanças que serão realizadas e posteriormente promover essas mudanças com o apoio de todo o corpo de colaboradores envolvidos no processo. Desse modo, treinamentos iniciais são feitos, palestras que apresentam a ISO ao staff acontecem e progressivamente as mudanças propostas passam a ser implementadas, novos treinamentos podem e devem ocorrer com o sistema já em funcionamento a fim de refinar o mesmo. A empresa, então, deve se preocupar em garantir que as alterações implementadas no SGQ ocorram corretamente, seguindo os padrões determinados, e atingindo os resultados iniciais esperados.

As normas para a fase de Implementação focam em propor diretrizes que auxiliem os gestores da qualidade quanto às técnicas estatísticas que podem ser úteis para a análise e acompanhamento dos dados quantitativos referidos na ISO 9001:2015, aos treinamentos necessários e as auditorias que devem ser primariamente executadas.

\subsection{Manutenção}

Para que um sistema de gestão gere resultados é necessário seu funcionamento continuado. A etapa Manutenção busca garantir e tomar as ações cabíveis e necessárias para que o SGQ mantenha sua produção, considerando, também, os feedbacks recebidos, sejam eles positivos ou negativos, e estratégias de resposta a eles. Além disso, uma vez que o SGQ já se encontra em funcionamento, nesta etapa se espera a realização de auditorias certificação, manutenção e recertificação. 
As Normas ISO de apoio ligadas a essa etapa são aquelas que focam em auditorias, não apenas por sua necessidade frequente como pelas iminentes auditorias ligadas certificação da ISO 9001, em treinamentos (ambas também propostas e de extrema importância na etapa Implementação), no tratamento de reclamações e no monitoramento e medição da satisfação de clientes.

\subsection{Melhoria}

Uma vez que atende aos padrões a que se propôs, a organização se volta não somente a manter todo o seu novo funcionamento como a buscar aperfeiçoá-lo. A etapa Melhoria foca nas possíveis novas decisões e ações a serem tomadas para colocar a empresa e seu SGQ voltados à melhoria contínua, buscando que a adequação, suficiência e eficácia da organização sejam sempre focos do aprimoramento do sistema.

Para tanto, existe uma norma ISO de suporte (ISO 9004) voltada a esse enfoque, que promove o melhor entendimento da empresa das áreas que apresentam maiores potencias de melhoria além de auxiliar a organização a elevar seus níveis de maturidade.

\section{Modelo de utilização e gerenciamento baseado nas normais ISO Não Certificáveis que apoiam a ISO 9001:2015}

O seguinte modelo busca, por meio da utilização e adaptação da Metodologia de Sistemas Soft de Checkland, propor planos de ação que podem ser seguidos pelo Gestor da Qualidade quando frente aos desafios enfrentados quanto a preparação para e implementação de um Sistema de Gestão da Qualidade baseado na ISO 9001. Se espera que o modelo possa ser utilizado de forma que melhor atenda às necessidades da organização, podendo ser seguido em sua totalidade ou existindo a seleção das Etapas e referentes Normas ISO que mais se adéquem às urgências que a empresa apresenta, sendo ele descrito no Quadro 3.

Quadro 3 - Modelo de Utilização e Gerenciamento para as normas ISO de Apoio 
Modelo de Utilização e Gerenciamento para as Normas ISO de Apoio

1. Decisão pela Mudança: O primeiro estágio é visto como o entendimento da organização da sua necessidade de adaptar-se à ISO 9001 ou de promover outras mudanças em seu SGQ, sendo esse o problema raiz a ser tratado

2. Definição da Etapa de Vida do SGQ: Para o segundo estágio, é prevista identificação da etapa(dentre as quatro etapas Planejamento, Implementação, Manutenção e Melhoria já esclarecidas no item anterior) em que a empresa se encontra, voltando suas atenções para ela.

3. Seleção de Mudanças + Análise CATWOE: O terceiro estágio, para o modelo proposto, é aquele que necessita de uma atenção especial. Uma vez identificada a etapa que será inicialmente trabalhada, é necessário que exista a identificação, dentre as Normas ISO de Apoio englobadas naquela etapa, de quais serão utilizadas e quais das suas informações são pertinentes ao momento da organização. Assim, para trabalhar a etapa identificada, é feita a análise CATWOE para identificar as perspectivas mais relevantes para aquele momento/etapa.

4. Projeto de Mudanças: No quarto estágio se busca a formulação do Projeto de Mudanças a serem feitas no sistema para o tópico escolhido com base na Etapa selecionada e nas Normas ISO de Apoio que ela indica. Ou seja, deve ser planejado como o Sistema funcionará de acordo com a implementação de tópico contidos nas Normas ISO não certificáveis

5. Comparação Projeto $x$ Realidade: O quinto estágio se preocupa em comparar o plano definido na etapa anterior com a realidade que a organização e seu SGQ se encontram, esclarecendo os pontos de melhoria a ser abordados e sua urgência.

6. Definição de Ações: O sexto estágio se aproxima muito da definição dada no Processo de Sete Estágios de Checkland, reunindo todas as informações até então levantadas, e definindo as ações a serem tomadas para a adequação ao plano definido no estágio quatro.

7. Ação: Assim como o sexto, o sétimo estágio deve ser visto de forma muito próxima ao definido no Processo de Sete Estágios. Devem ser promovidas as ações estabelecidas no estágio anterior, atribuindo responsabilidades àqueles envolvidos no processo, com a contínua avaliação dos resultados obtidos até que esses sejam satisfatórios 
De forma simplificada, os Sete Estágios de Utilização e Gerenciamento Baseados nas Normas ISO de Apoio podem ser vistos no fluxograma da Figura 1.

Figura 1 - Sete Estágios de Utilização e Gerenciamento Baseados nas Normas ISO de Apoio

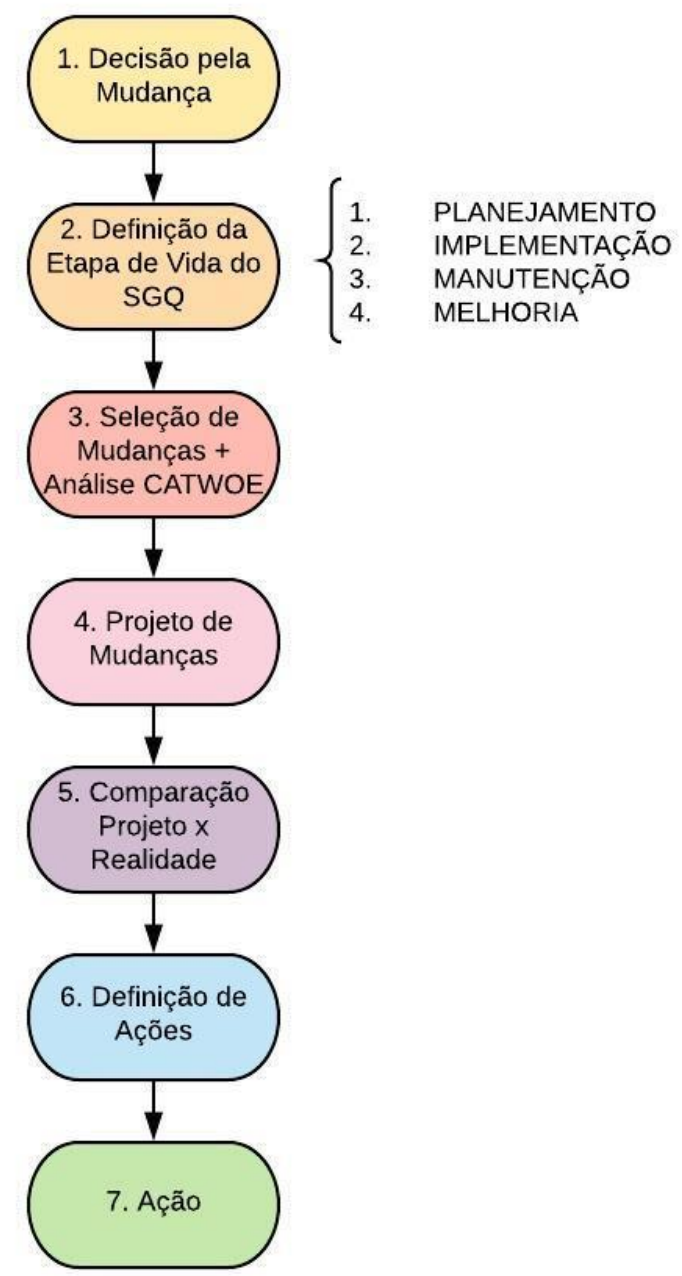

Fonte: Os Autores (2020)

Para o melhor entendimento do esquema apresentado na Figura 1, é pertinente o seguinte exemplo, uma organização com pouco tempo de mercado se encontra na etapa Planejamento de seu SGQ e pretende promover eventos de treinamento e integração de seus colaboradores, uma vez que esses necessitam se ambientar à empresa. Seria importante, então, que a mesma realizasse a avaliação de Nível de Maturidade segundo a ISO 10014:2008, já que esclarece quais princípios de gestão abordados na ISO 9001:2015 já estão presentes na organização, com especial atenção aos princípios de Envolvimento de Pessoas. A ISO 10018:2013 apresenta fatores e possíveis ações que a empresa pode tomar para fortalecer o envolvimento 
de pessoal e uma avaliação em cinco passos para a identificação dos níveis atuais de envolvimento e competência, também importante para a situação. Ademais, o D.O do CB-25 aponta os principais critérios a serem utilizados na seleção de um organismo de treinamento, como também um organismo certificador credenciado (OCC).

Uma vez notado em que as Normas ISO de Apoio da etapa auxiliam a organização, é possível que a gerência projete o que é esperado que o SGQ apresente após a utilização dessas informações e, ao comparar a situação planejada com a realidade da empresa, nota-se que é necessário treinamento, com maior urgência, dos líderes das etapas produtivas ligadas ao SGQ, já que esses acabam por influenciar seus subordinados, que podem passar por treinamento na sequência. Deve-se então, ser selecionado o organismo de treinamento de acordo com o indicado pelo D.O, buscando aquele que melhor tenha resultados, primeiramente, no treinamento de líderes. Simultaneamente a empresa pode estar, de forma interna, promovendo os cinco passos para a análise de seus níveis de envolvimento, e, uma vez devidamente treinados, os líderes estarão melhor preparados a determinar formas de agir que seus colaboradores devem seguir na busca de executar o trabalho a eles designado.

É necessário ressaltar que a empresa pensada no exemplo, pode, uma vez tomadas as atitudes necessárias, prosseguir para os estágios seguintes repetindo o sistema de análise. É também importante esclarecer que embora o exemplo utilizado parte da etapa Planejamento, uma empresa que identifique que se apresenta em fase distinta pode seguir a análise de acordo com a fase em que se encontra sem necessariamente ter de voltar às fases anteriores. De mesma forma, uma organização ainda que já tenha um SGQ bem estabelecido, pode preferir se enquadrar em etapas iniciais na busca de rever suas práticas ou realizar mudanças que acredita serem necessárias. Outra observação é que, como ocorreu no exemplo, nem sempre todas as normas ISO de apoio indicadas serão utilizadas no projeto de mudanças, estando a cargo do gestor da qualidade entender quais apresentam maior potencial e importância para seu sistema naquele momento.

\section{Considerações Finais}

O modelo proposto buscou formas de auxiliar os gestores da qualidade na implementação e melhoria de seus Sistemas de Gestão da Qualidade com base na ISO 9001:2015 por meio da utilização das Normas ISO não certificáveis que apoiam a ISO 9001. Este tema que vem ganhando mais espaço na literatura, fazendo uso de visões adaptadas do Processo de Sete 
Estágios proposto na Metodologia de Sistemas Soft de Checkland, dão base à gestão na tomada de decisões e ações que venham a aprimorar o SGQ já existente de uma organização e, se for a intenção, prepará-la para a certificação de qualidade. Estas normas ISO de apoio vêm ganhando espaço ao ficar claro o potencial de transformação para as organizações, já que elas são um detalhamento de pontos importantes de um SGQ como evidenciado por trabalhos de Murmura e Bravi (2017), Weckenmann et al (2015) e Zakerian et al (2017).

\section{REFERÊNCIAS}

Associação Brasileira de Normas Técnicas - ABNT. (2001). NBR ISO 10015: Diretrizes para treinamento. Rio de Janeiro.

Associação Brasileira de Normas Técnicas - ABNT. (2005). NBR ISO 10002: Diretrizes para o tratamento de reclamações nas organizações. Rio de Janeiro.

Associação Brasileira de Normas Técnicas - ABNT. (2005). NBR ISO 10007: Guia sobre técnicas estatísticas para ABNT NBR ISO 9001:2000. Rio de Janeiro.

Associação Brasileira de Normas Técnicas - ABNT. (2006). NBR ISO 10006: Sistemas de gestão da qualidade Diretrizes para a gestão da qualidade em empreendimentos. Rio de Janeiro.

Associação Brasileira de Normas Técnicas - ABNT. (2007). NBR ISO 10019: Diretrizes para a seleção de consultores de Sistema de Gestão da Qualidade e uso de seus serviços. Rio de Janeiro.

Associação Brasileira de Normas Técnicas - ABNT. (2008). NBR ISO 10014: Diretrizes para a percepção de benefícios financeiros e econômicos. Rio de Janeiro.

Associação Brasileira de Normas Técnicas - ABNT. (2013). NBR ISO 10004: Satisfação do cliente - Diretrizes para monitoramento e medição. Rio de Janeiro.

Associação Brasileira de Normas Técnicas - ABNT. (2015). NBR ISO 9001: Sistemas de gestão da qualidade: requisitos. Rio de Janeiro.

Associação Brasileira de Normas Técnicas - ABNT. (2018). NBR ISO 9004: Gestão da qualidade - Qualidade de uma organização - Orientação para alcançar o sucesso sustentado para o sucesso sustentado. Rio de Janeiro.

Associação Brasileira de Normas Técnicas - ABNT. (2018). NBR ISO 19011- Diretrizes para auditoria de sistemas de gestão. Rio de Janeiro.

BOYS, Kathryn A.; WILCOCK, Anne E.. Improving integration of human resources into quality management system standards. International Journal Of Quality \& Reliability Management. 2014, vol. 31, n. 7, p.738750, 29 jul. 2014. Emerald. http://dx.doi.org/10.1108/ijqrm-07-2012-0107.

BOYS, Kathryn; KARAPETROVIC, Stanislav; WILCOCK, Anne. Is ISO 9004 a path to business excellence? International Journal Of Quality \& Reliability Management. 2004, vol. 21, n. 8, p.841-860, out. 2004. Emerald. http://dx.doi.org/10.1108/02656710410551737. 
CHECKLAND, P. B. Towards a systems-based methodology for real-world problem solving. System Engineering. 1972, vol. 3, n. 2, winter. 1972.

HUGHES, Susan; KARAPETROVIC, Stanislav. ISO 10002 Complaints Handling System: a study. International Journal Of Quality \& Reliability Management. 2006, vol. 23, n. 9, p.1158-1175, dez. 2006. Emerald. http://dx.doi.org/10.1108/02656710610704258.

KARAPETROVIC, S.; WILLBORN, W.. ISO 9000 Quality Management Standards and Financial Investment Services. The Service Industries Journal. 2001, v. 21, n. 2, p.117-136, abr. 2001. Informa UK Limited. http://dx.doi.org/10.1080/714005025.

MAEKAWA, Rafael; CARVALHO, Marly Monteiro de; OLIVEIRA, Otávio José de. Um estudo sobre a certificação ISO 9001 no Brasil: mapeamento de motivações, benefícios e dificuldades. Gestão \& Produção. São Carlos, 2013, vol. 20, n. 4, p.763-779. 2013.

MURMURA, Federica; BRAVI, Laura. Empirical evidence about ISO 9001 and ISO 9004 in Italian companies. The Tqm Journal. 2017, vol. 29, n. 5, p.650-665, 14 ago. 2017. Emerald. http://dx.doi.org/10.1108/tqm-11-2016-0097.

RUSSELL, J.P. Use ISO 9004 to improve performance. Quality Progress. 2003, Vol. 36 No. 5, pp. 99 101.2003.

RIBIÈRE, Vincent M.; KHORRAMSHAHGOL, Reza. Integrating Total Quality Management and Knowledge Management. Journal Of Management Systems. 2004, vol. 16, n. 1, p.39-54, 2004.

SILVA, Avanilton Marinho da; MELO, Renata Maciel de. Uma abordagem multicritério para a seleção de serviços de consultoria e certificação de Sistemas de Gestão da Qualidade. Gestão \& Produção. 2017, vol. 25, n. 1, p.160-174, 28 set. 2017. FapUNIFESP (SciELO). http://dx.doi.org/10.1590/0104-530x2753-16.

SILVA, Gisele Cristina Sena da; MEDEIROS, Denise Dumke de. Metodologia de Checkland Aplicada à Implementação da Produção Mais Limpa em Serviços. Gestão \& Produção. 2006, v. 13, n. 3, p.411-422, 2006

WECKENMANN, Albert; AKKASOGLU, Goekhan; WERNER, Teresa. Quality management - history and trends. The Tqm Journal. 2015, vol. 27, n. 3, p.281-293, 13 abr. 2015. Emerald. http://dx.doi.org/10.1108/tqm11-2013-0125.

WILCOCK, A. et al. Use of ISO 9004: 2000 and other business excellence tools in Canada. International Journal Of Quality \& Reliability Management. 2006, vol. 23, n. 7, p.828-846, ago. 2006. Emerald. http://dx.doi.org/10.1108/02656710610679833.

ZAKERIAN, Mohsen et al. Studying the Items of Morning Reports based on ISO 10015 Standard in Teaching Hospitals of Mashhad University of Medical Sciences. International Journal Of Pediatrics. 2017, v. 5, n. 8, p.5587-5595, ago. 2017. Mashhad University of Medical Sciences. http://dx.doi.org/10.22038/ijp.2017.9042. 